\title{
Physiological study of larval fishes: challenges and opportunities
}

\author{
WARREN BURGGREN and TARA BLANK \\ Department of Biological Sciences, 1155 Union Circle \#305220, University of North Texas, Denton TX 76203-5017, \\ USA. E-mail: Burggren@unt.edu
}

\begin{abstract}
SUMMARY: Physiological studies of larval fishes have lagged far behind those of adults, yet offer tremendous opportunities for expanding our knowledge of the basic biology of both marine and freshwater fishes. Physiological studies of larval fishes can also improve research and management in areas of applied science, such as aquaculture, fisheries, and environmental assessment. Additionally, larval fishes can be highly effective as general animal models for understanding evolution, development and disease processes in vertebrates. While the small size of larval fishes may initially seem to preclude detailed physiological measurements, physiologists have taken advantage of larval transparency and permeability to drugs and toxins to collect many forms of quantitative physiological data. In this essay we present a number of microtechniques currently employed in larval fish to study the cardiovascular, muscular, neurological, and ionoregulatory systems. Several interesting phenomena, including allometry, developmental plasticity and epigenetic effects, are then discussed from the perspective of the specific contributions that have been or can be made by studies of fish larvae. Ultimately, the integration of larval fish physiology with studies of morphology and behaviour, is both highly feasibly and likely to strengthen basic and applied research in fishes.
\end{abstract}

Keywords: larval fish, physiological techniques, allometry, development, evolution, epigenetics.

RESUMEN: EsTUDIO FISIOLÓGICO DE LARVAS DE PECES: RETOS Y OPORTUNIDADES. - Los estudios de físiología en larvas de peces, están mucho más atrasados que los de peces adultos, sin embargo ofrecen enormes oportunidades para ampliar nuestro conocimiento sobre la biología básica de peces marinos y de agua dulce. Éstos también pueden mejorar la investigación y gestión en ciertas áreas de la ciencia aplicada, como la acuicultura, pesquerías y estudios ambientales. Además, las larvas de peces pueden ser eficaces como modelos animales para comprender la evolución, el desarrollo y los procesos de enfermedades en vertebrados. Mientras que su pequeño tamaño pudiera aparentar la imposibilidad de obtener medidas fisiológicas detalladas, los fisiólogos han aprovechado la transparencia larval y la permeabilidad a las drogas y toxinas para obtener diversas formas de datos físiológicos cuantitativos. En este ensayo, presentamos un número de microtécnicas empleadas actualmente en larvas de peces, para estudiar los sistemas cardiovascular, muscular, neurológico y de regulación iónica. Varios fenómenos interesantes, incluyendo la alometría, plasticidad del desarrollo y los efectos epigenéticos, se discuten desde la perspectiva de las contribuciones específicas, existentes o potenciales de los estudios en larvas de peces. En última instancia, la integración de la fisiología en las larvas de peces, con los estudios de morfología y comportamiento, no sólo son altamente factibles, sino una probable pieza clave en la investigación básica y aplicada en peces.

Palabras clave: larvas de peces, técnicas fisiológicas, alometría, desarrollo, evolución, epigenética.

\section{INTRODUCTION: WHY STUDY LARVAL FISH PHYSIOLOGY?}

The physiology of adult fishes has been studied for centuries, but the investigation of physiological processes in larval fishes is a somewhat modern em- phasis, enabled in part by technological advances. Consequently, answers to long-standing questions surrounding larval fishes are rapidly emerging and have been reported in a number of recent syntheses, most notably by Finn and Kappor (2008). Such research helps expand basic ichthyological knowl- 
edge-for example, by increasing our understanding of niche exploitation in marine and freshwater habitats. Evolutionary insights are also provided through physiological studies of larval fish because, in spite of the preferential studies of adults, embryonic and larval forms are an integral part of a species' evolutionary history. Studies of larval fish physiology can also be invaluable in terms of increasing the effectiveness of aquaculture research and fisheries management. Indeed, studies of energetics, growth and assimilation, and metabolism-to name a just few areas of physiological focus - can provide important details of life history not available from population counts, morphological measurements or observations of mortality. Finally, larval fish can also serve as a "bellwether" for the impacts of global climate change. Understanding the physiological responses of larval fishes to altered temperature, $\mathrm{pH}$, salinity, and oxygen concentration (as found in marine "dead zones", for example) may prove invaluable in managing the maintenance or recovery of fish populations.

While studying larval fishes to gain broader insights into fish biology is obvious, perhaps less obvious is the tremendous opportunity that larval fishes present as general animal models for understanding vertebrate development. Larval fishes can serve as broadly applicable models because early stages of development are surprisingly similar across vertebrate taxa. These similarities can be exploited and extrapolated so that discoveries made in a larval fish model could, for example, be transferred to research into human disease. The zebrafish (Danio rerio) is a wonderful example. A series of genetic screens (e.g. the 2000 Tübingen genetic screen) has led to the identification of several thousand mutations in the zebrafish heart, blood, blood vessels, bone, cartilage, nervous system, immune system and other cells, tissues and organs (http://zfin.org/). The ease of obtaining, maintaining, and breeding the zebrafish, along with its high fecundity and relatively short generation time, has rocketed the zebrafish to the forefront of developmental biology, and is helping to create new treatments for human disease.

While the zebrafish may have become the gold standard for modelling vertebrate development and studying disease processes, its characteristics and responses cannot, of course, be extrapolated to all vertebrates or even to all fishes, bearing in mind the complex interplay of environmental factors on growth, development, reproduction, and survival.
Marine fishes, for example, exhibit a wide variety of thresholds of tolerance for salinity, and many temperate freshwater fishes display a much broader range of thermal tolerance than does the tropical freshwater zebrafish. Acknowledging the need for a number of many diverse piscine models for studying developmental and environmental responses will only increase the value of larval fish research.

Having given just a few of the many possible answers to the question "Why study larval fish physiology", we now move on 1) to consider the many challenges presented by physiological investigation of larval fishes, and then 2) to present solutions to these challenges offered by the burgeoning field of micro-physiological techniques. We conclude this paper with a final section containing a few illustrative examples of studies of larval fish physiology.

\section{STUDYING LARVAL PHYSIOLOGY: TECHNOLOGICAL CHALLENGES AND SOLUTIONS}

Among the largest and most obvious challenge in studying the physiological processes of larval fishes is their extremely small size. Although physiological techniques abound for adult fishes, the reduced size of the embryonic and larval forms has made it necessary to rethink and reinvent methodologies for data collection. Ironically, however, characteristics of tiny larval fishes may offer the determined researcher advantages over studying adult fishes. Foremost, the body wall of embryos and early larval stages of almost all fishes is nearly transparent, enabling the visualization of most internal organs with relative ease using basic microscopic techniques. From these images a surprisingly diverse array of physiological measures can be made. The cardiovascular system of developing fishes is commonly studied with optical techniques, but other systems include muscles, neurons and sensory organs, and organs of the digestive system. Below we will introduce several possibilities for physiological measurements in marine and freshwater fish larvae, and provide basic citations allowing the readers to delve further themselves into the techniques.

\section{Cardiovascular system}

During vertebrate development the cardiovascular system is the first organ system to become fully 
functional. Almost any casual observer has noted the early beating of the newly formed heart when a larva is viewed with a microscope. Measurements of heart rate can be made in vivo by simply counting beats per minute using a stopwatch, or for a more permanent record for analysis, using a video camera attached to a microscope. Furthermore, many common hand-held video cameras with powerful zoom lenses can just be placed in a tripod and positioned over the eyepiece of a microscope without a dedicated camera and microscope lens attachment.

Moving beyond simple heart rate, measurement of additional parameters may be more technically demanding, but can also provide a more detailed record of embryonic/larval cardiovascular function and how it varies over time. Cardiac output of larval fishes, for example, can be derived in vivo from heart rate and stroke volume, the latter determined from dimensional changes of the heart during its systolic and diastolic cycling (Hou and Burggren, 1995; Fritsche and Burggren, 1996; Schwerte and Pelster, 2000; Schwerte and Fritsche, 2003; Burggren and Bagatto, 2008). Observations of blood velocity enables the quantitative calculation of blood flow and tissue perfusion, and can be determined in larval fishes and other tiny animals by laser Doppler flow probes (Koyama et al., 1975; Pelster and Bemis, 1991; Schwerte et al., 1997; Pelster and Burggren, 1996), spectroscopic analysis (Altimiras et al., 1995) and digital particle image velocimetry (Hove et al., 2003).

Continuous, dynamic recordings of larval blood pressure can be made using a servo-null micropressure system based on the insertion into the circulation of a tiny glass microelectrode similar to that used in neurophysiological recordings (Pelster and Bemis, 1991; Pelster and Burggren, 1991; Pelster and Burggren, 1996). When blood flow and blood pressure measurements are made concurrently, peripheral resistance values can be calculated, taking the analysis of integrated vascular function to a far higher level. Figure 1 indicates concurrently measured blood velocity and blood pressure in the little skate, Raja erinacea (Pelster and Bemis, 1991). Importantly, these basic measurements were possible nearly 20 years ago, and commercial apparatus for making them is now available from many vendors.

Methods for measuring vascular diameter in vivo have also been described, including digital vascular contrasting method (Schwerte and Pelster, 2000; Bagatto and Burggren, 2006), fluorescent microscopy (Isogai et al., 2001) and colour thresholding

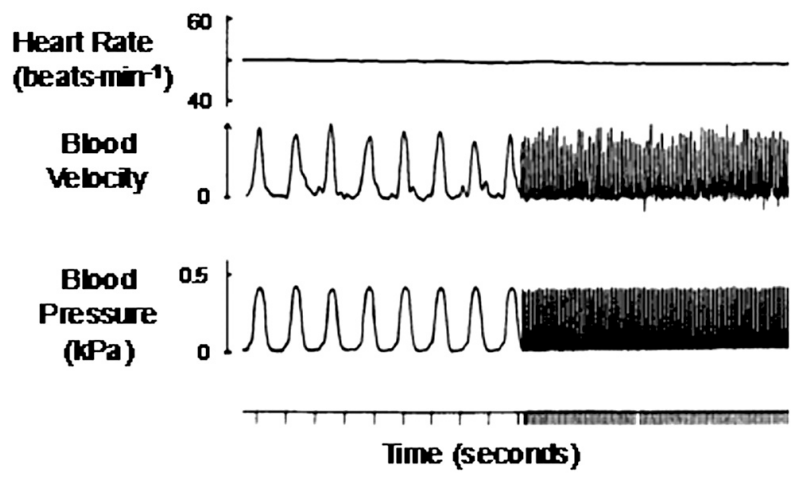

FIG. 1. - Cardiovascular measurements in a $44 \mathrm{~d}$ old, $120 \mathrm{mg}$ larva of the little skate, Raja erinacea. Intraventricular blood pressure was measured with a micro-pressure measurement system. Arterial blood velocity was determined with a bare pulsed Doppler crystal monitoring flow ejected from the anterior end of the conus arteriosus. Heart rate was derived from the primary blood pressure signal. Such measurements, innovative when Pelster and Bemis (1991) carried them out, are now routine. See text for additional details.

(Schwerte and Pelster, 2000). Figure 2 shows a vascular cast of a zebrafish larva created with the digital motion analysis technique (Fritsche et al., 2000). Much more than just producing attractive visual images of the vascular bed of the circulation, such images can be used to measure dynamic, acute changes in vessel diameter (Bagatto and Burggren, 2006). It is of course through vasoconstriction and vasodilation that vertebrates regulate regional blood flow. The maturation of physiological regulation can thus be judged by optically charting vasomotor activity in the developing circulation.
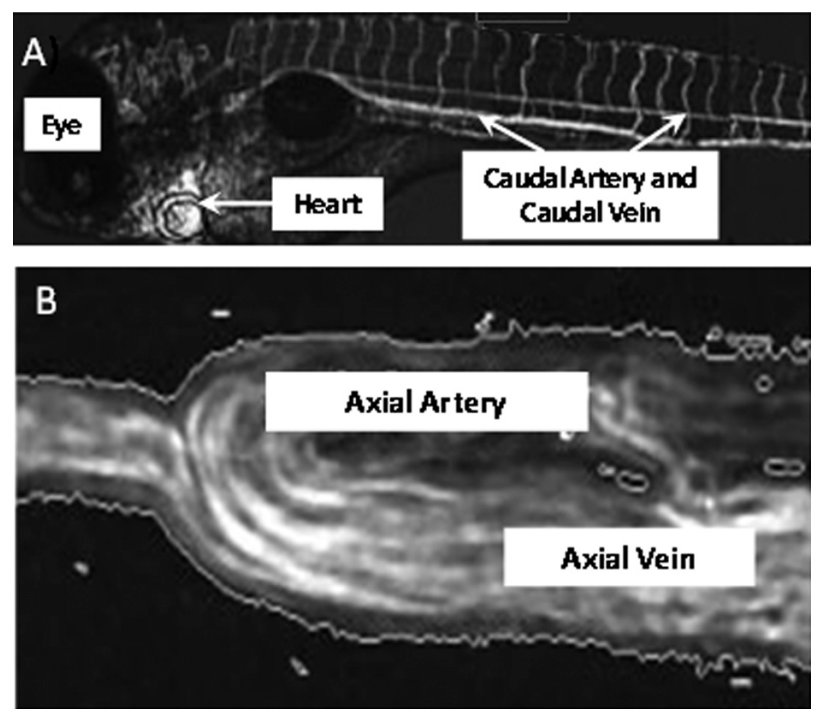

FIG. 2. - A computer-generated "vascular cast" of the microcirculation of a zebrafish larva. By capturing the pathway of moving erythrocytes, fine details of the perfused vasculature can be generated. Panel A reveals the overall circulation of the larva, including distinct vertebral vessels for each myotome in the trunk. Panel B shows in more detail the axial artery and vein. (After Fritsche et al., 2000) 
In vivo measurements of red blood cell concentration and blood perfusion can be made via digital motion analysis (Schwerte and Pelster, 2000; Schwerte et al., 2003), labelled erythrocytes/corpuscles (Weinstein et al., 1996), and by the use of GFP transgenic animals (Long et al., 1997). Even in vivo measurements of blood oxygenation and changes in blood oxygen transport may be performed by using spectroscopic ratio imaging (Shiga et al., 1990).

This section has provided just a snapshot of the techniques available for cardiovascular measurements in larval fishes. For a more thorough review of cardiovascular physiology microtechniques in small vertebrates, including larval fishes, see Schwerte and Fritsche (2003) and Burggren and Bagatto (2005).

\section{Haematology and hemostasis}

The development of red blood cells, white blood cells and platelets is crucial to physiological function through a fish's life span. However, the development of the process of hematopoiesis (blood cell formation) is still somewhat poorly understood in larval fishes (see Burggren and Bagatto, 2008). Fish share many biochemical pathways with humans, including those involved in blood coagulation (Van Vliet et al., 1985; Jagadeeswaran et al., 1999; Jagadeeswaran and Sheehan, 1999). To exploit these similarities, novel methods for studying the process of hemostasis (blood clotting) have been developed for larval fishes (primarily the zebrafish but readily transferrable to other species), including artificial induction of haemophilia (Jagadeeswaran and Liu, 1997) and the use of a mini-laser to induce thrombosis in tiny, regionalized areas of the circulation (Gregory et al., 2002; Jagadeeswaran et al., 2006). These techniques, in conjunction with larval exposure to a wide range of compounds, have proven useful for identifying substances that can reduce clotting time at the injury site-data that may eventually make their way into clinical trials for humans. However, understanding the clotting processes in fishes in general, and larvae in particular, may also be vitally important for understanding outbreaks of haemolytic diseases in marine fish populations and aquaculture settings (e.g. Guieng et al., 2006).

\section{Respiratory and Metabolic Physiology}

The respiratory and metabolic physiology of embryonic and larval fishes is also highly amenable to study, and investigations in these areas have actually made broad contributions to vertebrate physiology (e.g. Wieser, 1995, 2002; Hunt von Herbing, 2006). While the notion of measuring whole animal oxygen consumption in an animal as small as a young fish larva may seen intimidating, in fact whole animal oxygen consumption in very small fishes (or any other very small aquatic animal) can be readily measured by employing an appropriately sized glass syringe as a closed respirometer (e.g. Barrionuevo and Burggren, 1999). After a specified amount of time at a controlled temperature, a small volume of water from the syringe is injected into an oxygen electrode, yielding the oxygen partial pressure $\left(\mathrm{PO}_{2}\right)$ of the water in the respirometer. Knowing the volume of the water in the respirometer (determined from the markings on the syringe), the volume of the animal, the elapsed time in the respirometer, and the water $\mathrm{PO}_{2}$ before and after the measurement period, the oxygen consumption of the embryo or larva can be accurately determined (for a comprehensive description of both open and closed respirometry see Lighton, 2008). This method can also be used to determine the critical $\mathrm{PO}_{2}\left(\mathrm{P}_{\mathrm{CRIT}}\right)$ - the $\mathrm{PO}_{2}$ at which the larva makes the transition from an "oxygen regulator," capable of maintaining its oxygen consumption, to an "oxygen conformer", where its oxygen consumption falls along with the ambient $\mathrm{PO}_{2}$. By allowing the animal's metabolism to reduce the $\mathrm{PO}_{2}$ in the respirometer over several successive measurements, the $\mathrm{P}_{\text {CRIT }}$ can be readily revealed. These respirometry methods can be extended to include activity metabolism during swimming in individual larval fishes (Hunt von Herbing and Boutilier, 1996; Bagatto et al., 2001; Bagatto, 2005; Ruzicka and Gallager, 2006). Larvae are introduced into a sealed glass swim tunnel in which water is circulated at a known velocity. An oxygen probe monitoring water in the swim tunnel allows for constant evaluation of the water's oxygen content (Fig. 3). By determining the rate of oxygen decline during swimming bouts, the oxygen consumption, metabolic scope and other measurements can be determined in unrestrained, actively swimming larvae.

Microcalorimetry provides yet another avenue for obtaining metabolic rate, allowing the total metabolic rate (aerobic plus anaerobic) to be calculated from measurements of total heat output via direct calorimetry (McCollum et al., 2006). Microcalorimetry has been shown to be reliably used in studies of larval fishes (Finn et al., 1996; McCollum et al., 2006). 


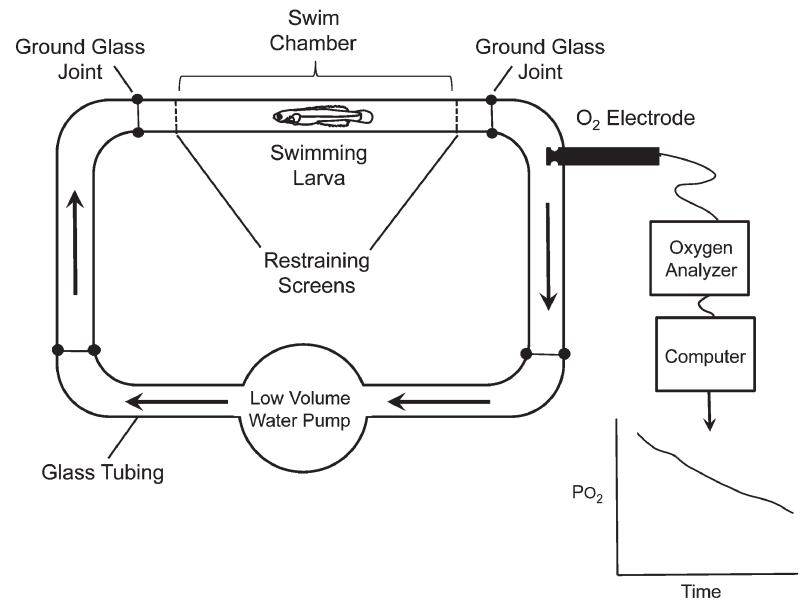

FIG. 3. - Schematic design of a closed respirometer that can be used for determining the oxygen consumption of swimming larval fishes. The larva is placed into the water-filled swimming chamber of the disassembled respirometer and restraining screens fitted so that the larva stays within the chamber. The respirometer is assembled, and the water pump turned on to create a known water velocity (flow direction indicated by arrows). An oxygen electrode monitors the decline in $\mathrm{PO}_{2}$ of the water as the fish swims. The oxygen consumption rate of the swimming larva can then be calculated from the rate of $\mathrm{PO}_{2}$ decline and the volume of the respirometer. (After Bagatto et al., 2001)

Embryonic and larval fishes exchange gases significantly, if not primarily, across their skin (Rombough, 1988). Microelectrodes can be used to determine area-specific cutaneous regions of intense oxygen consumption by determining the $\mathrm{PO}_{2}$ gradient in the diffusive boundary layer at various locations on the skin surface (Rombough, 1998).

\section{Osmoregulation and ionoregulation}

Understanding osmoregulation in embryonic and larval fishes is key to the effective management of natural populations of many marine species, which early in their life cycle may be exposed to considerable variation in salinity (e.g. in estuaries or in the rivers where anadromous species breed). In freshwater fish larvae, osmoregulation represents a major energetic cost, and understanding the tradeoffs between energy expenditure on osmoregulation and energy expenditure on assimilation may lead to important insights into fish development and growth (for a recent review see Kaneko and Hiroi, 2008).

The main site of ion exchange in adult fish is the gills, where chloride cells are responsible for active ion transport across the gill epithelia (e.g. Foskett and Scheffey, 1982). More recently, it has been proposed that the major function of the gills of late larval and juvenile zebrafish is ionoregulation, with the additional role of gas exchange only developing subsequently (Rombough, 2002, 2007a; Varsamos, 2005). Even before branchial development, however, chloride cells can also be found in the yolk-sac membrane and other body surfaces (Kaneko et al., 1995; Rombough, 2007a). The physiology of osmoregulation and the specific role of these cells (also referred to as mitochondria-rich cells or ionocytes), can be investigated with several methods, including fluorescent microscopy using a dye specific for mitochondria (e.g. DASPEI) or by immunochemistry with a specific antiserum for Na+, K+-ATPase (Kaneko and Hiroi, 2008). Such techniques have been employed, for example, to reveal that chloride cells of the yolk-sac membrane of embryos and larvae of the Mozambique tilapia, Oreochromis mossambicus, differ in size and density between those adapted to freshwater and those adapted to seawater (Ayson et al., 1994). Additional differences in the fine structure of these cells has been studied with both scanning and transmission electron microscopy (Shiraishi et al., 1997). The ion secreting and absorbing functions of the chloride cells can be detected with the vibrating probe technique (Foskett and Scheffey, 1982) and the chloride test, in which $\mathrm{Cl}^{-}$reacts with $\mathrm{Ag}^{+}$resulting in photosensitive $\mathrm{AgCl}$ (Kaneko and Shiraishi, 2001). Furthermore, the diffusion permeability coefficients of water, sodium, and chloride ions can be measured in larval fishes using radioisotope tracing techniques (Tytler and Bell, 1989).

Collectively, these and other tools and techniques are enabling expanded studies in larval fishes of osmoregulation, water balance and nitrogen excretion.

\section{Muscle physiology}

During early ontogeny, larval fishes experience extremely high rates of mortality, primarily as a result of predation. Thus, the rapid development of functional axial musculature is of fundamental importance in supporting the escape mechanism imperative for larval survival and has been the focus of intense study (see Müller, 2008 for a recent review). Of course, the morphology of muscle development can be studied in larval fishes using a number of well-established techniques, including histological preparations, which allow measurements of key muscle parameters. For example, mounting of white muscle and subsequent staining with toluidine blue can reveal distribution of white-fibre cross-sectional area, total white-muscle cross-sectional area, and 
total white-muscle fibre number (e.g. Albokhadaim et al., 2007). Red-muscle area can be obtained via succinate dehydrogenase staining (Nachlas et al., 1957). Electron microscopy reveals even more detail of muscle structure, including volume densities of mitochondria, myofibrils, the sarcotubular system, and sarcoplasm (Pelster et al., 2003).

Moving from morphology to physiology, the ontogeny of larval muscle function can be analyzed via high speed video recordings, which can reveal many aspects of larval swimming, including latency and initial muscle contraction times, tail-beat amplitude and frequency, stride length and swimming speed (e.g. Batty and Blaxter, 1992). Lateral displacement and curvature profiles can be created from the video recordings, enabling further evaluation of swimming kinematics (Müller and van Leeuwen, 2004). Examination of muscle function following acute or chronic exposure to environmental factors such as temperature (Martell and Kieffer, 2007), hypoxia (Matschak et al., 1995), and water velocity (Pelster et al., 2003) can indicate the extent to which muscle morphology and function can be altered in development. For a review of environmental effects on myogenesis in teleost fish, see Johnston (2006).

\section{Nervous System Physiology}

Proper development of the nervous system is crucial for the early survival of all animals. In larval fishes the peripheral nervous system is not only responsible for maintaining internal homeostasis, but also imperative for predatory avoidance and escape and food detection and acquisition. Reviews of the numerous sensory components of larval fishes can be found in Finn and Kapoor (2008).

Researchers have numerous techniques at their disposal for studying sensory and motor function during development in larval fishes. For example, non-invasive electroretinography permits measurements of the electrical response of the larval retina to light stimulation (Makhanov et al., 2004). In vivo recordings of synaptic potentials and action potentials are possible via intracellular labelling and patch clamp recording from individual sensory neurons, motoneurons and interneurons (Drapeau et $a l ., 1999)$. Neural pathway mapping, investigation of neural development and testing for axonal regeneration are possible in larval fishes using double- or triple-labelling techniques with fluorescent tracers (Zhang and McClellan, 1998) or even transgenic zebrafish larva expressing fluorescent proteins in central nervous system neurons (Higashijima, 2008; McClean and Fetcho, 2008).

\section{Exploiting pharmacological permeability}

Many of the experimental approaches mentioned above can be profitably expanded by the use of pharmacological agonists and antagonists. The thought of injecting pharmaceuticals into such small animals is daunting, but the body surface of many embryonic and larval fishes is highly permeable to a wide variety of substances, and this cutaneous permeability is being exploited by researchers as a way of introducing substances to the interior of the larva. Peptides, hormones, pharmaceuticals, organics and neurotransmitters can all be absorbed to varying degrees through the body wall and gills. The zebrafish embryo, for example, has been shown to be quite permeable to compounds ranging from warfarin to aspirin, and glucose to insulin (e.g. Jagadeeswaran and Sheehan, 1999; Jagadeeswaran et al., 2007). This innate permeability lends itself to a number of studies, ranging from basic development of regulatory systems to organized high-throughput screening of a myriad of biologically interesting substances including cardio-active drugs, antibiotics, growth hormones, and environmental pollutants.

\section{Immobilizing larvae for optical physiological measurements}

The physiological study of living larval fishes is often enhanced when they can be immobilized for observation, particularly if video images of internal process are being acquired. Immobilization can be achieved through anaesthetics such as MS-222 and ethanol (see Rombough, 2007b), muscle synapse block with curare or mechanical limitations to movement (e.g. placement in a glass capillary tube). Immobilization can also be achieved by placing larvae into special low-melting-point agar in its liquid form, which typically occurs above $25-27^{\circ} \mathrm{C}$. After immersion, the agar is quickly cooled to the desired temperature, immobilizing the larva in a now-solid agar block. The block can then be whittled down to the minimum size, and the surrounding gaseous or aquatic atmosphere adjusted to enhance oxygen diffusion through the agar and into the constrained larva. This technique allows the researcher to maintain the larva in a position favourable for micro- 
scopic examination without damaging the larva or significantly altering its short-term physiological status (van Raamsdonk et al., 1979; Schwerte and Pelster, 2000; Bagatto and Burggren, 2006).

Having discussed techniques for overcoming and even exploiting the small size of larval fishes, we now turn to especially promising opportunities that they present.

\section{PHYSIOLOGICAL STUDIES OF LARVAL FISHES: EXAMPLES OF INSIGHTS}

Fishes in general have many interesting characteristics that deserve further physiological analysis. While recent compilations indicate the burgeoning interest in fish larval physiology (e.g. Finn and Kapoor, 2008), most of what we know about fish physiology is still limited to the adult form. Although the possibilities of areas for expanding the physiology of larval fishes are nearly limitless, here we discuss just three possible areas of focus: allometry, developmental plasticity, and epigenetics. Importantly, by studying these phenomena in larval fishes, physiologists can not only contribute to fish biology but, through the service of fish larvae as a highly effective model, learn more about these phenomena in all vertebrates, including humans.

\section{Embryonic and larval physiology: determining the contributions of allometry}

Allometry refers to the disproportionate relationship between change in an animal's characteristics and change in its body size. Allometry permeates almost every aspect of the biology of animals, including that of larval fishes. The so-called "mouse to elephant curve" is a well-known colloquial expression of allometry, in which almost all aspects of a mouse's physiology, metabolism and morphology change substantially on a per gram basis when scaled up to the body mass of an elephant. Of course, there are similarly large body-mass ranges in fishes, with the $8 \mathrm{~mm}$ Paedocypris, the smallest known vertebrate, being at one end of the body size spectrum and the whale shark Rhiniodon (18000 mm) occupying the opposite end.

Most data on which allometric theory has been based have been derived from interspecific studies of adults. Intraspecific allometry, in which morphological and physiological variables are compared
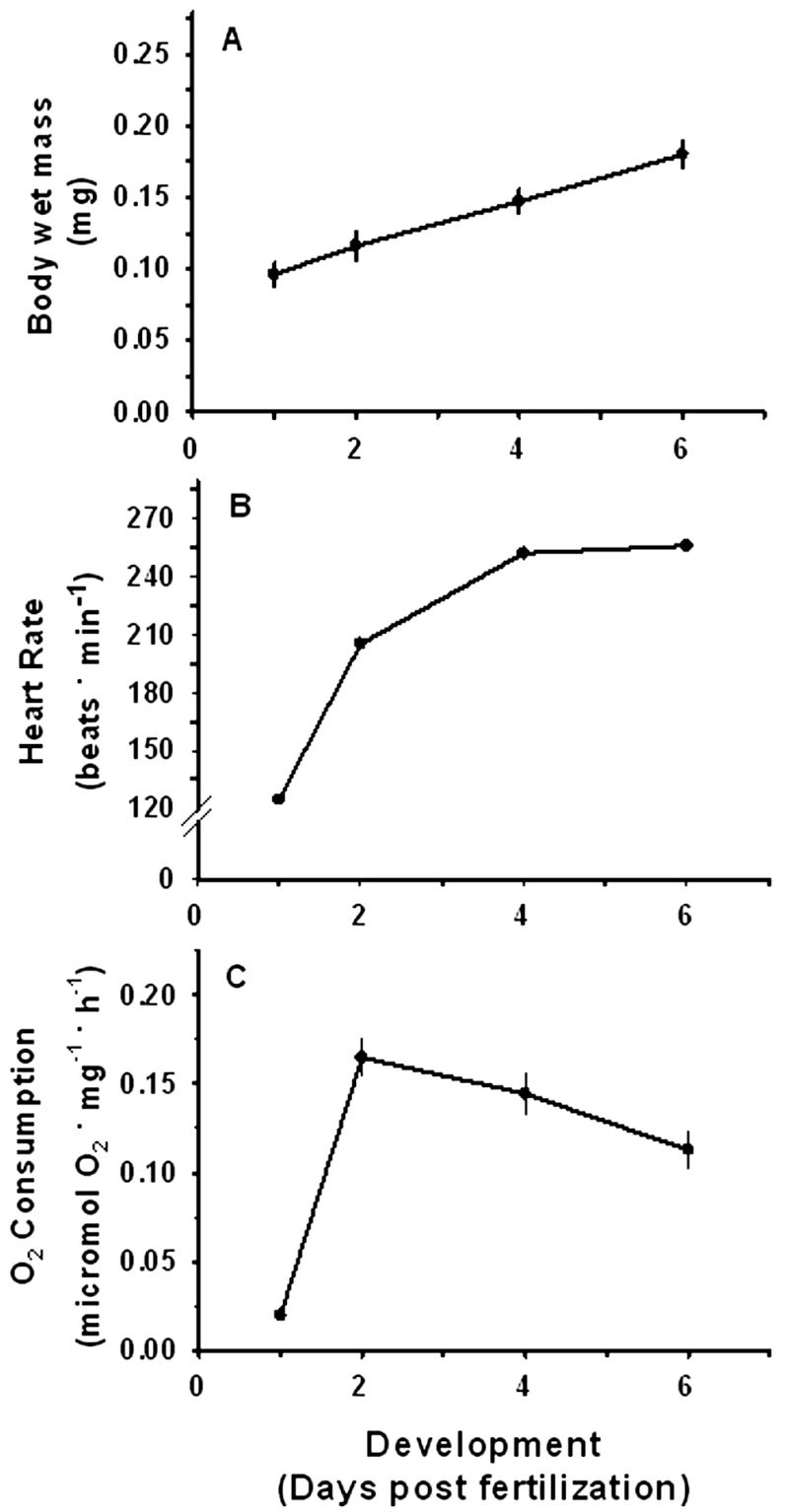

FIG. 4. - Body mass (A), heart rate (B) and mass-specific oxygen consumption (C) of early larvae of blue gourami (Trichogaster trichopterus). Contrary to interspecific allometric prediction, heart rate and oxygen consumption actually increase early in development (especially immediately following hatching), despite simultaneously increasing animal body mass during this same time period. (Blank, 2009).

within the framework of an individual's development, is less well understood and unfortunately is often dependent on dogmatic approaches imported from interspecific studies (Burggren, 2005). The extent to which allometry dictates physiological rates in developing animals is still an area of some contention. Certainly, mass-specific metabolic rate decreases with increasing body mass in a wide range of juvenile fishes (e.g. Rombough, 1988; Barrionuevo and Burggren, 1999; Pelster, 2008), but allometric 
equations cannot adequately predict the complex adjustments in metabolic rate or other physiological functions of embryonic and early larval fishes. A 20-fold increase in oxygen consumption between fertilization and hatching is not uncommon among fishes (Pelster, 2008), and mass-specific oxygen consumption as well as heart rate in the embryos/larvae of a wide variety of vertebrate (including fishes) either shows no change or even increases sharply early in development, even as body mass steadily increases-a direction of change contrary to that predicted by allometry (see Rombough 1988; Burggren and Warburton, 1994; Rombough and Moroz, 1997; Barrionuevo and Burggren, 1999; Bagatto 2005; Burggren and Bagatto, 2008; Pelster 2008). As an example of complex physiological pattern changes, consider physiological rate changes in the embryonic and early larval blue gourami (Trichogaster trichopterus) shown in Figure 4. Heart rate and oxygen consumption increase with development, even as wet body mass (yolk included) increases in this pre-feeding stage. While the results from the gourami reflect qualitatively those for zebrafish, for example (e.g. Barrionuevo and Burggren, 1999), Pelster (2008) appropriately cautions that the relationship between physiological rates and body mass in early development may be highly species-specific, ranging from conventional scaling relationships in developing cod (Finn et al., 2002) to independence from body mass in juvenile walleye (Rombough and Moroz, 1997) and a number of other fish species (see Giguere et al., 1988; Post and Lee, 1996).

The underlying mechanisms for these complex patterns of physiological rate change in larval vertebrates that sometimes reflect, and sometimes flout, allometric predictions are unclear, but there are several possibilities. For example, they may result from the developmental transition from hyperplastic growth (increasing organ or tissue size is a result of cell proliferation) to hypertrophic growth (organ or tissue growth is due to an increase in cell size) at about the time that physiological rates peak and then begin to decrease. Other possibilities include changes in the ontogenetic reorganization of tissues (e.g. Finn et al., 2002; Pelster, 2008), resulting in changes in red- to white-muscle ratios or the creation (or depletion) of large non-metabolic compartments such as oil droplets. The onset of feeding in early larvae could also result in a post-prandial boost to metabolic rate, as could the onset of swimming behaviour in formerly more sessile younger forms. Even the determination of what to include in the calculation of "body mass" is problematic in embryonic and early larval fishes and could lead to artefacts of calculation. Whatever the reason for these complex patterns of change in physiological rates in early development in lower vertebrates, larval fishes are ideal animals in which to further investigate these interesting and enigmatic phenomena.

\section{Developmental plasticity and heterokairy}

Developmental plasticity, in which the normal developmental trajectory of an animal can be modified by changes in the internal or external environment, is another area in which investigations of embryonic and larval fishes has made and will continue to make contributions to understanding this phenomenon in vertebrates generally. As an example, cardio-respiratory development of the zebrafish larva is influenced by water currents and environmental oxygen levels, resulting in numerous physiological adaptations leading to improved swimming efficiency and hypoxia tolerance (Pelster, 2002). Beyond quantitative modification of normal development lies more fundamental changes, such as the movement of developmental physiological landmarks (e.g. the onset of heart beat or the development of respiratory regulation) forward or backward in development of an individual. The term heterokairy has been used to describe such changes in the timing of the onset of developmental events at the level of the individual during its development (Fig. 5) (Spicer and Burggren, 2003; Spicer and Rundle, 2007). This phenomenon has been observed in various animal systems, including larval fishes. For example, larval anadromous salmonids treated with cortisol, growth hormone and insulin-like growth factor show accelerated onset of tolerance to seawater (McCormick et al., 1991; McCormick, 1994). Larval zebrafish reared in hypoxia show a reduced overall rate of development as measured by body morphology, but adrenergic responses and vasoconstriction are shifted to appear earlier in the developmental program (Bagatto, 2005). Overall, larval fishes show considerable promise for further investigations of heterokairy and other aspects of developmental plasticity.

\section{Epigenetics}

A final example of how embryonic and larval fishes can be used to answer general questions regarding physiological development involves the burgeoning 


\section{A Heterochrony}

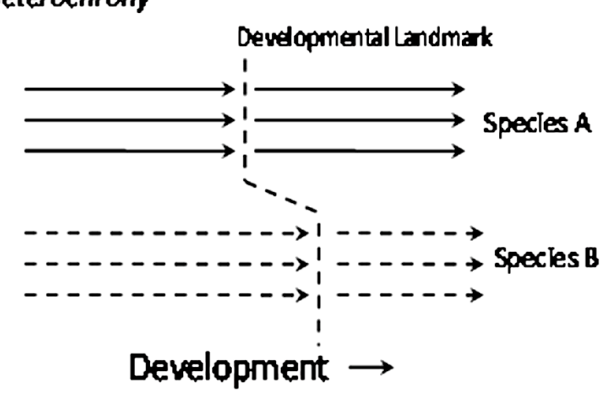

\section{B Heterokainy}

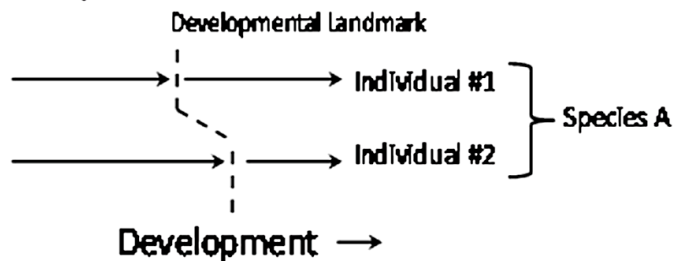

FIG. 5. - Interspecific versus intraspecific changes in the appearance of key developmental landmarks in a hypothetical group of organisms. Heterochrony is the term used to describe such changes in an evolutionary context-that is, between species (Gould, 1977; 1992). Heterokairy, however, describes such changes when they occur between individuals or between populations of the same species. Larval fishes provide excellent opportunities for investigating key concepts in both evolutionary and developmental biology and their interactions, especially concerning changes in development within

individuals and populations. See text for further discussion.

area of epigenetics - the study of heritable traits independent of alterations of the DNA sequence. Because gene expression ultimately determines phenotype (including physiological phenotype), regulation of this process can influence heritable transcription and can thus result in epigenetic physiological effects (e.g. Ho and Burggren, 2009). Two examples of this regulation include DNA methylation and histone modification. Another epigenetic mechanism involves direct transfer of maternal substances into the oocyte. Maternally produced mRNAs, transcription factors, hormones and immune factors can be deposited into the egg during oogenesis (Mousseau and Fox, 1998; Kudo, 2000; Ho, 2008), and can fundamentally influence embryonic and larval development. Even the amount of yolk itself comprises a form of epigenetic effect. In larval fish, for example, the amount of egg yolk present at fertilization influences adult phenotype by altering overall growth and metabolism (Heming and Buddington, 1988).

Embryonic and larval fishes are well-suited to the study of epigenetic effects, particularly as they affect physiological processes. Larval fishes have already been used to investigate epigenetic influences

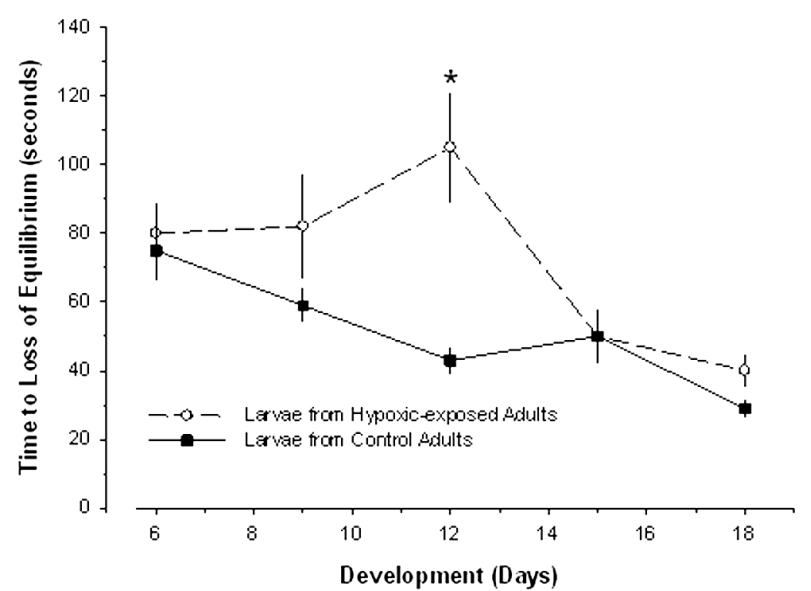

FIG. 6. - Time to loss of equilibrium in larval zebrafish (Danio rerio) exposed to acute, severe hypoxia $\left(3-5 \% \mathrm{O}_{2}\right)$. One larval population was derived from adults that had been chronically exposed to three weeks of hypoxia, while the other was derived from adults that had not been exposed to hypoxia. Mean values \pm s.e. are provided. An asterisk indicates significant difference from control population. (After Ho, 2008).

in vertebrates in the development of axial musculature (Kronnié, 2000), cardiovascular performance (Schwerte et al., 2005), feeding morphology and behaviour (Adams et al., 2003), the physiology and biochemistry of carbohydrate digestion (Geurden et al., 2007) and hypoxic tolerance (Ho, 2008). In the zebrafish Dana rerio, for example, adult fish chronically exposed to 2-4 weeks of moderate hypoxia and then returned to normoxia will subsequently produce offspring that after a week of development exhibit enhanced hypoxic resistance, as measured by increased time to loss of equilibrium in extreme hypoxia (Fig. 6). This particular epigenetic effect in zebrafish larvae suggests much additional study, such as the determination of whether the non-genomic generational transfer of hypoxia resistance results from enhanced blood oxygen binding, increased cardiac output, production of metabolic isozymes, etc.

Combining their transparency, relatively rapid growth and development, and relative ease of study, along with technical advances in physiological measurements, embryonic and larval fishes are likely to contribute substantially to the growing literature on the epigenetics of physiological phenotype.

\section{CONCLUSIONS}

Larval stages have long been recognized as an area of great importance to the overall understanding of the biology of fishes, but studies have tended 
to focus more on their morphology and behaviour, in which the testing of hypotheses is viewed as more tractable for such small organisms. To counter the perception that detailed physiological investigation remains elusive, we have discussed numerous techniques for examining cardiovascular, respiratory, metabolic, hemostatic, muscular and neural physiology. We have also indicated that opportunities exist for investigation in a number of additional areas of physiology, including cell signalling, acid-base regulation, nutrition and energetics, immunology, endocrinology and renal physiology.

These physiological techniques open up a myriad of possible ways in which studies of larval fish can be modified and expanded. For example, in an environmental challenge protocol that considers whether a larva lives or dies, we can move to a higher level of sophistication by asking "How did the animal die?", "What can be done to prevent mortality?" or even "What physiological signals can we measure to indicate stress without having to wait for larval death?" We believe that the integration of physiological observations into future studies of fish embryos and larvae focusing on marine and freshwater aquaculture, fisheries science and environmental impact assessment will be extraordinarily powerful.

\section{ACKNOWLEGEMENTS}

This study was supported by NSF Operating Grant 0614815 to WB, and by Grants-in-Aid of Research from Sigma Xi and SICB to TB. We are grateful for the suggestions for improvement of this manuscript made by anonymous reviewers.

\section{REFERENCES}

Adams, C.E., C. Woltering and G. Alexander. - 2003. Epigenetic regulation of trophic morphology through feeding behaviour in Arctic char, Salvelinus alpines. Biol. J. Linnean Soc., 78 (1): 43-49.

Ayson, F.G., T. Kaneko, S. Hasegawa and T. Hirano. - 1994. Development of mitochondrion-rich cells in the yolk-sac membrane of embryos and larvae of tilapia, O. mossambicus, in fresh water and seawater. J. Exp. Zool., 270: 129-135.

Albokhadaim, I., C.L. Hammond, C. Ashton, B.H. Simbi, S. Bayol, S. Farrington and N. Stickland. - 2007. Larval programming of post-hatch muscle growth and activity in Atlantic salmon (Salmo salar). J. Exp. Biol., 210: 1735-1741.

Altimiras, J., A. Aissaoui. and L. Tort. - 1995. Is the short-term modulation of heart rate in teleost fish physiologically significant? Assessment by spectral analysis techniques. Braz. J. Med. Bio. Res., 28: 1197-1206.

Bagatto, B. - 2005. Ontogeny of cardiovascular control in zebrafish (Danio rerio): effects of developmental environment. Comp.
Biochem. Physiol. A, 141: 391-400.

Bagatto, B. and W. Burggren. - 2006. A three-dimensional functional assessment of heart and vessel development in the larva of the zebrafish (Danio rerio). Physiol. Biochem. Zool., 79(1): 194-201.

Bagatto, B.B. Pelster and W.W. Burggren. - 2001. Growth and metabolism of larval zebrafish: effects of swim training. J. Exp. Biol., 204: 4335-4343.

Barrionuevo, W.R. and W.W. Burggren. - 1999. O 2 consumption and heart rate in developing zebrafish (Danio rerio): influence of temperature and ambient $\mathrm{O}_{2}$. Am. J. Physiol. Regul. Integr. Comp. Physiol., 45: R505-R513.

Blank, T. 2009. Cardio-respiratory ontogeny and the transition to bimodal respiration in an air-breathing fish, the blue gourami (Trichogaster trichopterus): morphological and physiological development in normoxia and hypoxia. Ph.D. Dissertation, University of North Texas, Denton, Texas, U.S.A.

Burggren, W.W. - 2005. Developing animals flout prominent assumptions of ecological physiology. Comp. Biochem. Physiol. A, 141(4): 430-439.

Burggren, W.W. and B. Bagatto. - 2008. Cardiovascular Anatomy and Physiology. In: R.N. Finn and B.G. Kapoor. (eds.), Fish Larval Physiology, pp. 119-161. Science Publishers, Enfield, New Hampshire

Burggren, W.W. and S. Warburton. - 1994. Patterns of form and function in developing hearts: Contributions from non-mammalian vertebrates. Cardioscience 5(3): 183-191.

Drapeau, P., D.W. Ali, R.B. Buss and L. Saint-Amant. - 1999. In vivo recording from identifiable neurons of the locomotor network in the developing zebrafish. J. Neuro. Meth., 88: 1-13.

Finn R.N. and B.G. Kapoor (eds.). - 2007. Fish Larval Physiology. Science Publishers, Enfield, New Hampshire

Finn, R.N., I. Ronnestad, T. van der Meeren and H.J. Fyhn. - 2002. Fuel and metabolic scaling during the early life stages of Atlantic cod Gadus morhua. Mar. Ecol. Prog. Ser. 243: 217-234.

Finn, R.N., J. Widdows and H.J. Fyhn. - 1996. Calorespirometry of developing embryos and yolk-sac larvae of turbot (Scophthalmus maximus). Mar. Biol., 122: 57-163.

Foskett, K.J. and C. Scheffey. - 1982. The chloride cell: definitive identification as the salt secreting cell in teleosts. Science, 215: 164-166.

Fritsche, R. and W.W. Burggren. - 1996. Developmental responses to hypoxia in larvae of the frog Xenopus laevis. Amer. J. Physiol., 271: R912-R917

Fritsche, R., T. Schwerte and B. Pelster. - 2000. Nitric oxide and vascular reactivity in developing zebrafish, Danio rerio. Am. J. Physiol. Regul. Integr. Comp. Physiol., 279: R2200-R2207.

Geurden, I., M. Aramendi, M. Zambonino-Infante and S. Panserat. - 2007. Early feeding of carnivorous rainbow trout (Oncorhynchus mykiss) with a hyperglucidic diet during a short period: effect on dietary glucose utilization in juveniles. Am. J. Physiol. Regul. Integr. Comp. Physiol., 292: R2275-R2283.

Giguere L.A., B. Cote, and J. F. St-Pierre. - 1988. Metabolic rates scale isometrically in larval fishes. Mar Ecol. Prog. Ser 50: 13-19.

Gould, S.J. - 1977. Ontogeny and Phylogeny. Harvard University Press, Cambridge.

Gould, S.J. - 1992. Heterochrony. In: E. Fox and E. Lloyds (eds.), Keywords in Evolutionary Biology, pp. 158-167. Harvard University Press, Cambridge.

Gregory, M., R. Hanumanthaiah and P. Jagadeeswaran. - 2002. Genetic analysis of hemostasis and thrombosis using vascular occlusion. Blood Cells Molec. Disease, 29(3): 286-295.

Guieng, L., D. Zhao, L. Huang, J. Sun, D. Gao, H. Wang, Y. Tan and L. Liang. - 2006. Identification and phylogenetic analysis of Vibrio vulnificus isolated from diseased Trachinotus ovatus in cage mariculture. Aquaculture, 261(1): 17-25.

Heming, T.A. and Buddington, R.K. - 1988. Yolk absorption in embryonic and larval fishes. In: W.S. Hoar and D.J. Randall (eds.), Fish Physiology, Vol XI, pp. 407-446. Academic Press, London.

Higashijima, S. - 2008. Transgenic zebrafish expressing fluorescent proteins in central nervous system neurons. Dev. Growth. Differ., 50(6): 407-13.

Ho, D. 2008. Morphological and physiological developmental consequences of epigenetic processes in the chicken embryo (Gallus gallus domesticus) and the zebrafish larva (Danio rerio). Ph.D. 
Dissertation. Univ. North Texas.

Ho, D. and W.W. Burggren. - 2009. Epigenetics and transgenerational transfer: a comparative physiological perspective. Submitted to J. Exp. Biol.

Hou, P-C.L. and W.W. Burggren. - 1995. Blood pressures and heart rate during larval development in the anuran amphibian Xenopus laevis. Amer. J. Physiol., 269: R1120-R1125.

Hove, J.R., R.W. Koster, A.S. Forouhar, G. Acevedo-Bolton, S.E. Fraser and M. Gharib. - 2003. Intracardiac fluid forces are an essential epigenetic factor for embryonic cardiogenesis. Nature, 421: $172-177$.

Hunt von Herbing, I. (2006) The physiological basis for metabolic scaling in animals: A developing perspective. In: S.J. Warburton, W.W. Burggren, B. Pelseter, C.L. Reiber and J. Spicer. (eds.), Comparative Developmental Physiology, pp. 83-98. Oxford University Press, Oxford.

Hunt von Herbing, I. and Boutilier, R.G. (1996). Activity and metabolism of larval Atlantic cod (Gadus morhua) from Scotian shelf and Newfoundland source populations. Mar. Biol. 124: 607-617.

Isogai, S., M. Horiguchi and B.M. Weinstein. - 2001. The vascular anatomy of the developing zebrafish: an atlas of embryonic and early larval development. Dev. Biol., 230: 278-301.

Jagadeeswaran, P. and Y. Liu. - 1997. A hemophilia model in zebrafish: analysis of hemostasis. Blood Cells Molec. Disease, 23(3): $52-57$

Jagadeeswaran, P., R. Paris and P. Rao. - 2006. Laser-induced thrombosis in zebrafish larvae: a novel genetic screening method for thrombosis. Meth. Mol. Med., 129: 187-195.

Jagadeeswaran, P., Y. Liu and J.P. Sheehan. - 1999. Analysis of hemostasis in zebrafish. Meth. Cell Biol., 59: 337-357.

Jagadeeswaran, P., V. Kulkarni, M. Carrillo and S. Kim. - 2007. Zebrafish: from hematology to hydrology. J. Thrombosis Haemostasis, 5(s1): 300-304.

Jagadeeswaran, P. and J.P. Sheehan. - 1999. Analysis of blood coagulation in the zebrafish. Blood Cells Molec. Disease, 25(4): 239-249.

Johnston, I.A. - 2006. Environment and plasticity of myogenesis in teleost fish. J. Exp. Biol., 209: 2249-2264.

Kaneko, T., S. Hasegawa, Y. Takagi, M. Tagawa, M. and T. Hirano. - 1995. Hypoosmoregulatory ability of eyed-stage embryos of chum salmon. Mar. Biol., 122: 165-170.

Kaneko, T. and J. Hiroi. - 2008. Osmo- and ionoregulation. In: R.N. Finn and B.G. Kapoor (eds.), Fish Larval Physiology, pp. 163183. Science Publishers, Enfield

Kaneko, T. and K. Shiraishi. - 2001. Evidence for chloride secretion from chloride cells in the yolk-sac membrane of Mozambique tilapia larvae adapted to seawater. Fish Sci., 68: 1-9.

Kaneko, T. and J. Hiroi. - 2008. Osmo- and Ionoregulation. In: R.N Finn and B.G. Kapoor. (eds.), Fish Larval Physiology, pp. 163183. Science Publishers, Enfield, New Hampshire.

Koyama, T., H. Mishina and T. Asakura. - 1975. Study of microcirculation in web of frog (Xenopus laevis) by using laser Doppler microscope. Experientia, 31: 1420-1422.

Kronnié, G. - 2000. Axial muscle development in fish. Basic Appl. Myol., 10(6): 261-267.

Kudo, S. - 2000. Enzymes responsible for the bactericidal effect in extracts of vitelline and fertilization envelops of rainbow trout eggs. Zygote, 8: 257-265.

Lighton, J. - 2008. Measuring Metabolic Rates: A Manual for Scientists. Oxford University Press, Oxford, U.K.

Long, Q., A. Meng, H. Wang, J.R. Jessen, M.J. Farrell and S. Lin. - 1997. GATA-1 expression pattern can be recapitulated in living transgenic zebrafish using GFP reporter gene. Development 124: 4105-4111.

Makhanov, Y.V., O. Rinner and S.C.F. Neuhauss. - 2004. An inexpensive device for non-invasive electroretinography in small aquatic vertebrates. J. Neurosci. Meth., 135: 205-210.

Martell, D.J. and J.D. Kieffer. - 2007. Persistent effects of incubation temperature on muscle development in larval haddock (Melanogrammus aeglefinus). J. Exp. Biol., 210: 1170-1182.

Matschak, T.W., N.C. Stickland, A.R. Crook and T. Hopcroft. 1995. Is physiological hypoxia the driving force behind temperature effects on muscle development in embryonic Atlantic salmon (Salmo salar)? Differentiation, 59(2): 71-77.

McLean, D.L. and J.R. Fetcho. - 2008. Using imaging and genetics in zebrafish to study developing spinal circuits in vivo. Dev.
Neurobiol., 68(6): 817-34.

McCollum, A., J. Geubtner and I. Hunt von Herbing. - 2006. Metabolic cost of feeding in Atlantic cod (Gadus morhua) larvae using microcalorimetry. ICES J. Mar. Sci., 63: 335-339.

McCormick, S.D., W.W. Dickhoff, J. Duston, R.S. Nishioka and H.A. Bern. - 1991. Developmental differences in the responsiveness of gill sodium, potassium ATP-ase to cortisol in salmonids. Gen. Comp. Endocrinol., 84: 308-317.

McCormick, S.D. - 1994. Ontogeny and evolution of salinity tolerance in anadromous salmonids: hormones and heterochrony. Estuaries, 17(1A): 26-33.

Mousseau, T. A. and C.W. Fox (eds.). - 1998. Maternal effects as adaptations. Oxford University Press, New York.

Müller, U.K. - 2008. Swimming and muscle. In: R.N. Finn and B.G. Kapoor (eds.), Fish Larval Physiology, pp. 523-549. Science Publishers, Enfield, New Hampshire.

Müller, U.K. and J.L. van Leeuwen. - 2004. Swimming of larval zebrafish: ontogeny of body waves and implications for locomotory development. J. Exp. Biol., 207: 853-868.

Nachlas, M.M., K.C. Tsou, E. Desouza, C.S. Cheng and A.M. Seligman. - 1957. Cytochemical demonstration of succinic dehydrogenase by the use of pnitrophenyl substituted ditetrazolium. $J$. Histochem., 5: 420-436.

Pelster, B. - 2002. Developmental plasticity in the cardiovascular system of fish, with special referent to the zebrafish. Comp. Biochem. Physiol. A. Mol. Integr. Physiol. 133(3): 547-553.

Pelster, B. - 2008. Gas Exchange. In: R.N. Finn and B.G. Kapoor (eds.), Fish Larval Physiology, pp. 91-117. Science Publishers, Enfield, New Hampshire.

Pelster, B. and W.E. Bemis. - 1991. Ontogeny of heart function in the little skate, Raja erinacea. J. Exp. Biol., 156: 387-398.

Pelster, B. and W. Burggren. - 1991. Central arterial hemodynamics in larval bullfrogs (Rana catesbeiana): developmental and seasonal influences. Am. J. Physiol. Regul. Integr. Comp. Physiol., 260: R240-R246.

Pelster, B. and W.W. Burggren. - 1996. Disruption of hemoglobin oxygen transport does not impact oxygen-dependent physiological processes in developing embryos of zebra fish (Danio rerio). Circ. Res., 79: 358-362

Pelster, B., A.M. Sanger, M. Siegele and T. Schwerte. - 2003. Influence of swim training on cardiac activity, tissue, capillarization, and mitochondrial density in muscle tissue of zebrafish larvae. Am. J. Physiol. Regul. Integr. Comp. Physiol., 285: R339-R347.

Post, J.R and J.A. Lee. - 1996. Metabolic ontogeny of teleost fishes. Can. J. Fish. Aquat. Sci. 53: 910-923.

Rombough, P.J. - 1988. Respiratory gas exchange, aerobic metabolism, and effects of hypoxia during early life. In: W.S. Hoar and D.J. Randall (eds.), Fish Physiology, vol. XIA, pp. 59-161. Academic Press, London.

Rombough, P.J. - 1998. Partitioning of oxygen uptake between the gills and skin in fish larvae: a novel method for estimating cutaneous oxygen uptake. J. Exp. Biol., 201: 1763-1769.

Rombough, P.J. - 2002. Gills are needed for ionoregulation before they are needed for $\mathrm{O}_{2}$ uptake in developing zebrafish Danio rerio. J. Exp. Biol., 205: 1787-1794.

Rombough, P.J. - 2007(a). The functional ontogeny of the teleost gill: which comes first, gas or ion exchange? Comp. Biochem. Physiol. A, 148: 732-742.

Rombough, P.J. - 2007(b). Ontogenetic changes in the toxicity and efficacy of the anaesthetic MS222 (tricaine methanesulfonate) in zebrafish (Danio rerio) larvae. Comp. Biochem. Physiol. A Mol Integr. Physiol., 148(2): 463-9.

Rombough, P.J. and B.M. Moroz - 1997. The scaling and potential importance of cutaneous and branchial surfaces in respiratory gas exchange in larval and juvenile walleye Stizostedion vitreum. J. Exp. Biol. 200: 2459-2468.

Ruzicka, J.J. and Gallager, S.M. 2006. Deep Sea Res. Part II, 53(2324): 2708-2734

Schwerte, T. and R. Fritsche. - 2003. Understanding cardiovascular physiology in zebrafish and Xenopus larvae: the use of microtechniques. Comp. Biochem. Physiol. A, 135: 131-145.

Schwerte, T. and B. Pelster. - 2000. Digital motion analysis as a tool for analyzing the shape and performance of the circulatory system in transparent animals. J. Exp. Biol., 203: 1659-1669.

Schwerte, T., M. Axelsson, S. Nilsson and B. Pelster. - 1997. Effects of vagal stimulation on swimbladder blood flow in the European eel Anguilla anguilla. J. Exp. Biol., 200: 3133-3139. 
Schwerte, T., D. Überbacher and B. Pelster. - 2003. Non-invasive imaging of blood cell concentration and blood distribution in zebrafish Danio rerio incubated in hypoxic conditions in vivo. J. Exp. Biol., 206: 1299-1307.

Schwerte, T., S. Voigt and B. Pelster. - 2005. Epigenetic variations in early cardiovascular performance and hematopoiesis can be explained by maternal and clutch effects in developing zebrafish (Danio rerio). Comp. Biochem. Physiol. A Mol. Integr. Physiol., 141(2): 200-209.

Shiga, T., N. Tateishi and N. Maeda. - 1990. Visible spectroscopic technique for flowing erythrocytes in capillary. Biorheology, 27: 389-397.

Shiraishi, K., T. Kaneko, S. Hasegawa, S. and T. Hirano. - 1997. Development of multicellular complexes of chloride cells in the yolk-sac membrane of tilapia (Oreochromis mossambicus) embryos and larvae in seawater. Cell Tissue Res., 288: 583-590

Spicer, J.I. and W.W. Burggren. - 2003. Development of physiological regulatory systems: altering the timing of crucial events. Zoology, 106: 91-99.

Spicer, J.I. and S.D. Rundle. - 2007. Plasticity in the timing of physiological development: physiological heterokairy-what is it, how frequent is it, and does it matter? Comp. Biochem. Physiol. A Mol. Integr. Physiol., 148(4): 712-719.

Tytler, P. and M.V. Bell. - 1989. A study of diffusional permeability of water, sodium and chloride in yolk-sac larvae of cod (Gadus morhua L.). J. Exp. Biol., 147: 125-132.

van Raamsdonk, W., W. Mos, G. Tekronnie, C.W. Pool and P. Mi- jzen. - 1979. Differentiation of the musculature of the teleost Brachydanio rerio. II. Effects of immobilization on the shape and structure of somites. Acta. Morphol. Neerl. Scand., 17(4): 259-273.

Van Vliet, K.J., G.L. Smit, J.J. Pieterse, H.J. Schoonbee and J.H. Van Vuren. - 1985. thromboelastographic diagnosis of blood coagulation in two freshwater fish species. Comp. biochem. Physiol. A Comp. Physiol., 82: 19-21.

Varsamos, S., C. Nebel and G. Charmantier. - 2005. Ontogeny of osmoregulation in postembryonic fish: a review. Comp. Biochem. Physiol. A Mol. Integr. Physiol., 141(4): 401-429.

Weinstein, B.M., A.F. Schier, S. Abdelilah, J. Malicki, L. SolnicaKrezel, D.L. Stemple, D.Y. Stainier, F. Zwartkruis, W. Driever and M.C. Fishman. - 1996. Hematopoietic mutations in the zebrafish. Development, 123: 303-309.

Wieser W. - 1995. Energetics of fish larvae, the smallest vertebrates. Acta Physiol. Scand. 154(3): 279-290.

Wieser W. - 2002. Comparative and medical physiology: a theme with three variations. J. Comp. Physiol., B. 172(8): 651-657.

Zebrafish Information Network (ZFIN). University of Oregon, Eugene, OR 97403-5274; World Wide Web URL: http://zfin.org/.

Zhang, L. and A.D. McClellan. - 1998. Fluorescent tracers as possible candidates for double labeling of descending brain neurons in larval lamprey. J. Neuro. Meth., 85: 51-62.

Received October 3, 2008.Accepted June 26, 2009.

Published online October 5, 2009. 